\title{
Combined high-frequency and Doppler ultrasound in early diagnosis of atrophoderma of Pasini and Pierini*
}

\author{
Elisa de Oliveira Barcaui ${ }^{1}$, Antonio Carlos Pires Carvalho ${ }^{1}$, Juan Piñeiro-Maceira ${ }^{2,3}$, Carlos Baptista \\ Barcaui $^{2}$
}

DOI: http://dx.doi.org/10.1590/abd1806-4841.20198112

\begin{abstract}
Atrophoderma of Pasini and Pierini is a skin disorder affecting dermal collagen and is clinically characterized by well-defined plaques of depressed skin. Histopathological changes are subtle, and in most cases, the diagnosis requires a comparative study with healthy skin from the same anatomical site. High frequency ultrasound is a useful imaging method for diagnosis of atrophic skin changes. A case is presented in which ultrasound can support the clinical and the histopathological diagnosis of atrophoderma of Pasini and Pierini.
\end{abstract}

Keywords: Scleroderma, localized; Skin diseases; Ultrasonography; Ultrasonography, doppler

\section{INTRODUCTION}

Atrophoderma of Pasini and Pierini (APP) is a disease of unknown etiology that predominantly affects young women and is characterized by asymptomatic skin atrophy. APP manifests as a single or multiple sharply demarcated, usually hyperpigmented lesions of varying size, preferably located on the back. ${ }^{1}$ It is a matter of debate whether APP is a forme fruste or early form of morphea or an isolated entity. Some authors have suggested a role of Borrelia burgdorferi in the genesis of the disease. ${ }^{2}$ Histopathological changes are subtle, and in most cases, the diagnosis requires a comparative study with healthy skin from the same anatomical site. The epidermis appears normal, and there may be increased pigmentation of the basal layer. Recent research using multiphoton microscopy revealed alterations not in the density of either collagen or elastic fiber but in their organization. ${ }^{3}$ Skin appendages and subcutaneous tissue remain unchanged. ${ }^{1}$

\begin{abstract}
Diagnostic imaging methods that allow noninvasive real-time investigation without the use of radiation are increasingly being used in dermatology. The development of high-resolution ultrasound equipment combined with high-frequency transducers has enabled the use of this technique in the diagnosis, monitoring and treatment of physiological and pathological changes of the skin and its appendages. ${ }^{4}$ Ultrasound imaging at 20 to $25 \mathrm{MHz}$ allows differentiation between skin layers, and when it is combined with color or power Doppler ultrasound, it is possible to estimate blood flow in the area of interest. ${ }^{5}$
\end{abstract}

\footnotetext{
Received 21 January 2018.

Accepted 06 June 2018.

Study conducted at the Universidade Federal do Rio de Janeiro, Rio do Janeiro, RJ, Brazil.

Financial support: None.

Conflict of interest: None.

Department of Radiology, Universidade Federal do Rio de Janeiro, Rio do Janeiro, RJ, Brazil.

Discipline of Dermatology, Faculdade de Ciências Médicas, Universidade do Estado do Rio de Janeiro, Rio de Janeiro, RJ, Brazil.

Discipline of Pathological Anatomy, Faculdade de Ciências Médicas, Universidade do Estado do Rio de Janeiro, Rio de Janeiro, RJ, Brazil.
}

MAILING AdDRESS:

Elisa de Oliveira Barcaui

E-mail: ebarcaui@gmail.com

(C2019 by Anais Brasileiros de Dermatologia 


\section{CASE REPORT}

A 30-year-old woman presented with an asymptomatic lesion on the trunk, which had persisted for three months. Physical examination revealed a single, ovoid, hyperpigmented and slightly depressed lesion, measuring $10 \mathrm{~cm}$ on the major axis and $5 \mathrm{~cm}$ on the minor axis, localized in the left infrascapular region. There were no signs of inflammation in the affected area (Figure 1A). On palpation, no induration was noted.

Laboratory tests including an examination for rheumatic activity and serology for Borrelia burgdorferi were negative.
Histopathology of lesional skin biopsy specimens revealed hyperpigmentation of the basal layer of the epidermis, mild perivascular inflammatory infiltrate, and collagen bundles that appear slightly hyalinized in the dermis (Figure 1B).

Ultrasound examination was performed using a 22-MHz linear-array transducer and Doppler color-flow imaging at $12.5 \mathrm{MHz}$ (MyLab Touch; Esaote, Genoa, Italy), with application of a copious amount of aqueous gel and minimal transducer pressure. The comparative study between the left (affected) and right (healthy) scapular regions showed decreased dermal thickness in the lesion compa-
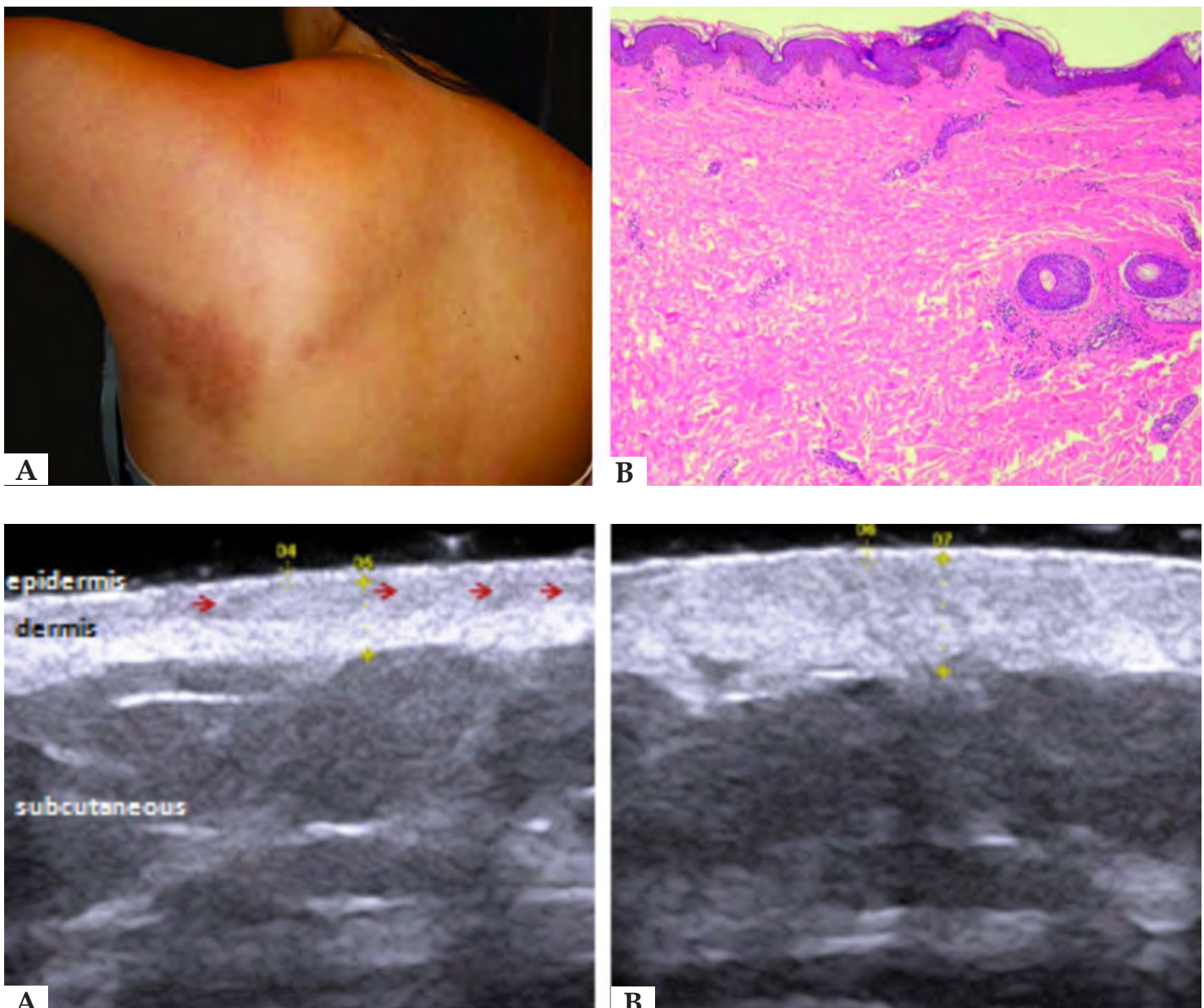

A

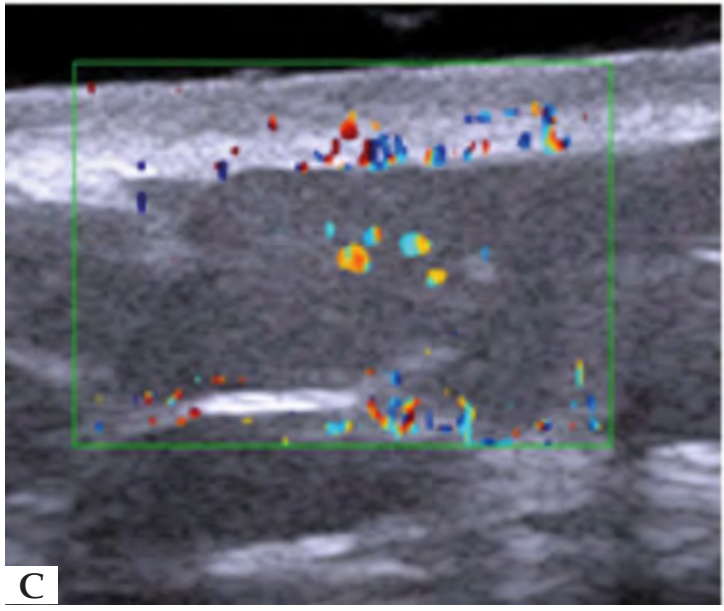

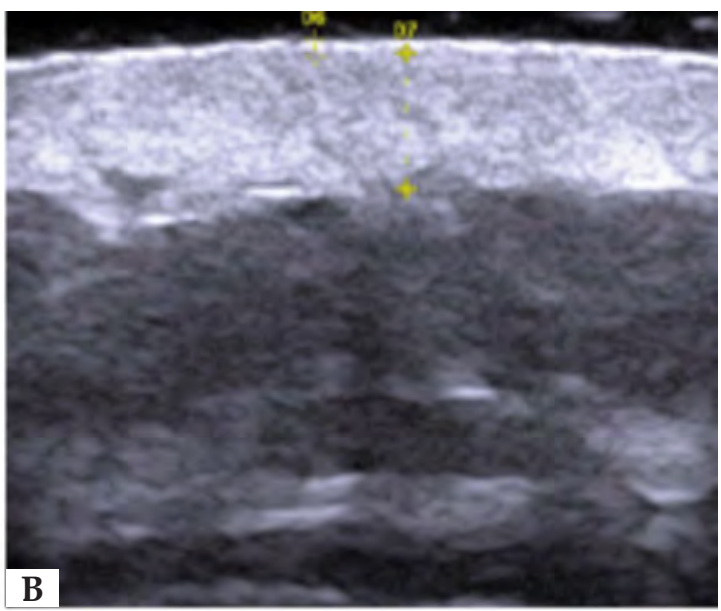

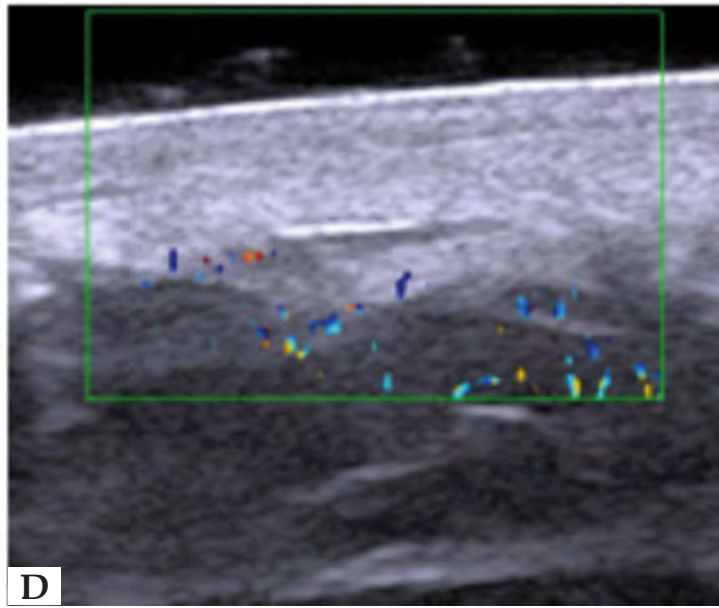

Figure 1:

A: Hyperpig-

mented, slightly depressed lesion in the infrascapular region. B: Hyperpigmentation of the basal layer of the epidermis, perivascular inflammatory infiltrate, and slightly hyalinized collagen bundles in the reticular dermis (Hematoxylin \& eosin, $x 100$ )

\section{Figure 2:}

A and B: HFUS, cross-sectional view. A: left scapular region, affected area.

B: right scapular region, control. The comparative study shows decreased dermal thickness in the affected area and presence of hypoechoic regions in the dermis, suggesting the preserved skin appendages $(\rightarrow)$. Unchanged epidermis and subcutaneous tissue. $\mathrm{C}$ and D: Color Doppler ultrasound. C: Increased blood flow in the dermis of the affected area D: compared with the contralateral healthy area 
red with normal skin (Figures 2A and B). The color Doppler imaging showed increased vascularity of the affected area (Figures $2 \mathrm{C}$ and D). Hypoechoic images were visible inside the dermis at both sites, indicating the presence of skin appendages.

The diagnosis of APP was made based on the correlation between clinical and ultrasound findings, because without comparative specimens, the histopathology of lesion specimens was inconclusive.

\section{DISCUSSION}

In high-frequency ultrasound (HFUS), morphea can be differentiated from APP by the presence, in the early stage of disease, of low echogenicity and increased skin thickness, representing ede$\mathrm{ma}$; and in the late stage, there is decreased skin thickness and increased echogenicity, corresponding to fibrosis and skin thinning. ${ }^{6,7}$

The literature is unclear whether APP is a distinct entity or a form of localized scleroderma. Considering the findings presented in this case together with the results of Vieira-Damiani et al., ${ }^{3}$ the authors reiterate the proposal that APP could be classified into classic and morphea-like variants.
HFUS is a useful tool for early diagnosis of atrophic skin changes, especially at early stages, in which histopathological changes are subtle and require comparative study with healthy tissue for a better definition. Thus, HFUS can support the clinical and the histopathological diagnosis, obviating the need for large biopsies or collection of a second sample. ${ }^{8,9}$ This reduces patient discomfort and the number of underdiagnosed cases, in which early initiation of treatment is important for the therapeutic response. HFUS is a noninvasive, painless procedure, and serial measurements can be used to monitor lesion progression. ${ }^{10}$ However, because its application is relatively recent in dermatology, further studies based on a higher number of patients are necessary to confirm these findings and standardize the terminology and criteria for evaluating disease progression, which would increase its applicability in routine dermatological practice.]

\section{REFERENCES}

1. Saleh Z, Abbas O, Dahdah MJ, Kibbi AG, Zaynoun S, Ghosn S. Atrophoderma of Pasini and Pierini: a clinical and histopathological study. J Cutan Pathol. 2008;35:1108-14.

2. Santos M, Ribeiro-Rodrigues R, Talhari C, Ferreira LC, Zelger B, Talhari S. Presence of Borrelia burgdorferi "Sensu Lato" in patients with morphea from the Amazonic region in Brazil. Int J Dermatol. 2011;50:1373-8.

3. Vieira-Damiani G, Lage D, Christofoletti Daldon PÉ, Tibúrcio Alves $\mathrm{CR}$, Cintra ML, Metze K, et al. Idiopathic atrophoderma of Pasini and Pierini: a case study of collagen and elastin texture by multiphoton microscopy. J Am Acad Dermatol. 2017;77:930-7.

4. Kleinerman $R$, Whang $T B$, Bard RL, Marmur ES. Ultrasound in dermatology: principles and applications. J Am Acad Dermatol. 2012;67:478-87.

5. Jasaitiene D, Valiukeviciene $S$, Linkeviciute $G$, Raisutis $R$, Jasiuniene E, Kazys R. Principles of high-frequency ultrasonography for investigation of skin pathology. J Eur Acad Dermatol Venereol. $2011 ; 25: 375-82$
6. Bagatin E, Caetano LVN, Soares JLM. Ultrasound and dermatology: basis principles and main applications in dermatologic research. Expert Rev Dermatol. 2013;8:463-77.

7. Buense $R$, Duarte IAG, Bouer M. Localized scleroderma: assessment of the therapeutic response to phototherapy. An Bras Dermatol. 2012;87:63-9.

8. Nouri S, Jacobe H. Recent developments in diagnosis and assessment of morphea. Curr Rheumatol Rep. 2013;15:308.

9. Abe I, Ochiai T, Kawamura A, Muto R, Hirano Y, Ogawa M. Progressive idiopathic atrophoderma of Pasini and Pierini: the evaluation of cutaneous atrophy by 13-MHz B-mode ultrasound scanning method. Clin Exp Dermatol. 2006;31:462-4.

10. Barcaui EO, Carvalho ACP, Lopes FPPL, Piñeiro-Maceira J, Barcaui CB. High frequency ultrasound with color Doppler in dermatology. An Bras Dermatol. 2016;91:262-73.

\footnotetext{
AUTHORS ${ }^{\prime}$ CONTRIBUTIONS
$\begin{array}{ll}\text { Elisa De Oliveira Barcaui } & \text { (D) ORCID } \\ 0000-0002-9487-7860\end{array}$

Conception and planning of the study, Elaboration and writing of the manuscript, Obtaining, analyzing and interpreting the data, Critical review of the literature

Antonio Carlos Pires Carvalho $\quad$ (D) ORCID 0000-0003-2447-7607

Approval of the final version of the manuscript, Effective participation in research orientation, Critical review of the manuscript

Juan Piñeiro-Maceira $\quad$ (D) ORCID 0000-0002-8021-2374

Approval of the final version of the manuscript, Critical review of the manuscript

Carlos Baptista Barcaui $\quad$ (1) ORCID 0000-0002-3303-3656

Approval of the final version of the manuscript, Conception and planning of the study, Effective participation in research orientation, Critical review of the manuscript
}

How to cite this article: Barcaui EO, Carvalho ACP, Piñeiro-Maceira J, Barcaui CB. Combined high-frequency and Doppler ultrasound in early diagnosis of atrophoderma of Pasini and Pierini. An Bras Dermatol. 2019;94(4):473-5. 